\title{
Effect of ferrihydrite on 2,4,6-trinitrotoluene biotransformation by an aerobic yeast
}

\section{Authors: Irina V. Khilyas, Ayrat M. Ziganshin, Andy J. Pannier, \& Robin Gerlach}

NOTICE: The final publication is available at Springer via http://dx.doi.org/10.1007/ s10532-012-9611-4.

Khilyas IV, Ziganshin AM, Pannier AJ, Gerlach R, "Effect of ferrihydrite on 2,4,6-trinitrotoluene biotransformation by an aerobic yeast," Biodegradation, September 2013 24(5): 631-644. 


\title{
Effect of ferrihydrite on 2,4,6-trinitrotoluene biotransformation by an aerobic yeast
}

\section{Irina V. Khilyas • Ayrat M. Ziganshin・Andy J. Pannier・Robin Gerlach}

I. V. Khilyas A. M. Ziganshin

Department of Microbiology, Kazan (Volga Region) Federal University, ul., Kremlyovskaya 18, Kazan 420008, The Republic of Tatarstan, Russia

\author{
A. J. Pannier \\ Department of Chemistry and Life Science, United States Military Academy, West Point, NY 10996, USA
}

\section{A. J. Pannier R. Gerlach}

Center for Biofilm Engineering, Montana State University, Bozeman, MT 59717, USA

R. Gerlach

Department of Chemical and Biological Engineering, Montana State University, Bozeman, MT 59717, USA

\section{Abstract}

This study investigated the impact of ferrihydrite on the pathway and rate of 2,4,6-trinitro-toluene (TNT) transformation by Yarrowia lipolytica AN-L15. The presence of ferrihydrite in the culture medium decreased the rate of TNT biotransformation but resulted in the accumulation of the same TNT metabolites as in the absence of ferrihydrite, albeit at slightly different concentrations. Transformation products observed included aromatic ring reduction products, such as hydride-Meisenheimer complexes, and nitro group reduction products, such as hydroxylamino- and amino-dinitrotoluenes. Independently of the presence of ferrihydrite the subsequent degradation of the hydride complex(es) resulted in the release of nitrite followed by its conversion to nitrate and nitric oxide at the low $\mathrm{pH}$ values observed during yeast cultivation. Nitric oxide generation was ascertained by electron spin resonance spectroscopy. In addition, increased Fe3- reduction was observed in the presence of TNT and Y. lipolytica. This study demonstrates that in the presence of yeast cells, TNT-hydride complexes were formed at approximately the same level as in the presence of ferrihydrite, opening up the possibility of aromatic ring cleavage, instead of promoting the production of potentially toxic nitro group reduction products

in the

presence

of

iron

minerals

Keywords: 2,4,6-Trinitrotoluene Biodegradation Ferrihydrite Yeast Nitroaromatics

\section{Introduction}

Nitroaromatic compounds are generally of anthropo-genic origin and considered recalcitrant in the envi-ronment (Heiss and Knackmuss 2002; Stenuit et al. 2005; Stenuit and Agathos 2010; Singh et al. 2012). Environmental contamination by nitroaromatic com-pounds is the result of their extensive long-term use in military and industry as well as during the manufac-ture of drugs, fungicides, insecticides, and dyes. 
The fate of 2,4,6-trinitrotoluene (TNT) has been the focus of much research since soil and water contamination has been observed worldwide. For example, there are many areas in Germany, the United States of America and Russia, where explosives were produced and tested during World War II and beyond, and where solid phase residues of TNT can be found, which can serve as a long-term source of surface and groundwater pollution (Rieger and Knackmuss 1995; Spain 1995).

Toxicity, mutagenicity and carcinogenicity of TNT and some of its nitro group reduction metabolites have been described (e.g. Harter 1985; Yinon 1990; Leung et al. 1995). The aromaticity of TNT combined with the symmetrical insertion of three electron-withdrawing nitro substituents on the aromatic ring results in a very stable chemical compound that is resistant to microbial degradation (Esteve-Núñez et al. 2001; Ye et al. 2004). While the nitro groups are reduced fairly easily into hydroxylamino-dinitrotoluenes (HADNTs) and amino-dinitrotoluenes (ADNTs) by many bacteria and fungi, the biologically mediated cleavage of the aromatic system or removal of functional groups is challenging. Additional metabolites observed during TNT nitro group reduction in the presence of bacteria and fungi include diamino-nitrotoluenes (DANTs), tetranitro-azoxytoluenes, tetranitro-azotoluenes, aminodimethyl-tetranitrobiphenyls, diarylamines as well as 2,4,6-triaminotoluene. The extent of their formation generally depends on which microbial strain or consortium is involved and on the geochemical conditions under which transformation is being initiated (e.g. Michels and Gottschalk 1994; Fiorella and Spain 1997; Hawari et al. 1999; Huang et al. 2000; Pak et al. 2000; Borch et al. 2005; van Dillewijn et al. 2008b). Several studies have described that some microorganisms can produce unique reductive enzymes, which catalyze the addition of hydride ions to TNT under aerobic conditions resulting in the formation of hydride- and dihydride-Meisenheimer complexes followed by their destruction and accumulation of nitrite (French et al. 1998; Pak et al. 2000; van Dillewijn et al. 2008b; Wittich et al. 2009). In our previous works (Ziganshin et al. 2007, 2010a, b) we demonstrated the ability of aerobic yeasts to eliminate nitro groups from TNT and to oxidize nitrite to nitrate during TNT transformation via hydride-Meisenheimer complexes. Mineralization of TNT by other fungal strains has also been described (e.g. Michels and
Gottschalk 1994; Scheibner et al. 1997; Eilers et al. 1999; van Aken et al. 1999; Hawari et al. 1999). In addition, phytoremediation of TNT using unmodified (Adamia et al. 2006; Nepovim et al. 2005) and transgenic plant systems has been investigated (Hannink et al. 2003; van Dillewijn et al. 2008a; Rylott et al. 2011).

Since iron is one of the most abundant elements in the biosphere, iron-containing minerals are likely to participate in transformation reactions at sites contaminated with nitroaromatic compounds (Agrawal and Tratnyek 1996; Oh et al. 2002; Borch et al. 2005; Hofstetter et al. 2006; Eyers et al. 2008; Boparai et al. 2010). A number of reports have demonstrated the abiotic and biotic transformation of nitroaromatic compounds in the presence of iron. In earlier work, the influence of $\mathrm{Fe}^{0}$ on TNT removal from polluted soil and water was investigated (e.g. Hundal et al. 1997), and degradation of TNT was achieved in the presence of $\mathrm{Fe}^{0}$ and $\mathrm{H}_{2} \mathrm{O}_{2}$, while $\mathrm{Fe}^{0}$ in combination with biotic treatment resulted in accumulation of amino derivatives. The abiotic/biotic reduction of TNT by $\mathrm{Fe}^{2+}$ has also been reported (Hofstetter et al. 1999), resulting in accumulation of nitro group reduction products. $\mathrm{Fe}^{2+}$ was adsorbed to goethite in abiotic experiments, and Geobacter metallireducens GS-15 was used as a producer of $\mathrm{Fe}^{2+}$ in columns filled with $\mathrm{FeOOH}-$ coated sand. Dithionite-reduced sediments containing $\mathrm{Fe}^{2+}$ have also been reported to abiotically transform TNT to 2,4-DANT and 2,6-DANT, which further degraded to unknown metabolites (Boparai et al. 2008). Borch et al. (2005) showed that the presence of ferrihydrite in the culture medium during TNT transformation by a fermenting bacterium Cellulomonas sp. strain ES6 resulted in enhanced production of ADNTs. Eyers et al. (2008) demonstrated that Pseudomonas aeruginosa ESA-5 under anoxic conditions reduced nitro groups to amino derivatives and denitrated TNT with considerable nitrite release into the medium containing ferrihydrite. However, the body of literature describing biological reduction of TNT in the presence of $\mathrm{Fe}$-containing minerals under aerobic conditions is small, even though molecular oxygen might have a significant effect on Fe-oxidation and reduction processes (Morgan and Lahav 2007).

To the best of our knowledge, denitration of TNT by strictly aerobic yeast cells in the presence of ferrihydrite has not been demonstrated previously. Therefore, the main goal of this study was to investigate the 
influence of ferrihydrite as an example of metastable $\mathrm{Fe}$-containing minerals on the pathway and rate of TNT transformation by Yarrowia lipolytica AN-L15.

\section{Materials and methods}

\section{Chemicals}

TNT, 2,4-dinitrotoluene (2,4-DNT) (purity, $99 \%$ ) were purchased from ChemService (West Chester, PA); 2-amino-4,6-dinitrotoluene (2-ADNT), 4-amino2,6-dinitrotoluene (4-ADNT) (purity, $99 \%$ ) were obtained from Supelco (Bellefonte, PA); 2-hydroxylamino-4,6-dinitrotoluene (2-HADNT) (purity, $97 \%$ ), 4-hydroxylamino-2,6-dinitrotoluene (4-HADNT) (purity, $96 \%$ ) and other potential metabolites of TNT nitro group reduction were received from AccuStandard (New Haven, CT). Sodium N,N-diethyldithiocarbamate (DETC) as the nitric oxide (NO) spin trapping reagent, S-Nitroso-N-acetylpenicillamine (SNAP) as the $\mathrm{NO}$ donor, $\mathrm{NaBH}_{4}$ and all other chemicals and reagents were purchased from Sigma-Aldrich (USA).

Yeast strain and culture conditions

Experiments were carried out using the yeast strain $Y$. lipolytica AN-L15, which is unable to utilize nitrite or nitrate as the sole nitrogen source (Ziganshin et al. 2010a). Yarrowia lipolytica AN-L15 was deposited into the Russian National Collection of Industrial Microorganisms under a collection number of VKPM Y-3492. Yarrowia lipolytica was grown aerobically at $30{ }^{\circ} \mathrm{C}$ for 1 day on Sabouraud glucose agar medium containing (per liter) $10 \mathrm{~g}$ of glucose, $10 \mathrm{~g}$ of peptone, $5 \mathrm{~g}$ of yeast extract, $0.25 \mathrm{~g}$ of $\mathrm{NaCl}$, and $20 \mathrm{~g}$ of agar. Yeast cells were harvested, washed with $16 \mathrm{mM}$ phosphate buffer ( $\mathrm{pH} 5.5$ or 7.0) and added into $125 \mathrm{~mL}$ Erlenmeyer flasks containing $30 \mathrm{~mL}$ of synthetic medium as described previously (Ziganshin et al. 2007, 2010a). The synthetic medium was composed of $28 \mathrm{mM}$ glucose, $7.6 \mathrm{mM}\left(\mathrm{NH}_{4}\right)_{2} \mathrm{SO}_{4}$, $2 \mathrm{mM} \mathrm{MgSO}_{4}$ and was buffered with $16 \mathrm{mM} \mathrm{K}-\mathrm{Na}-$ phosphate buffer to $\mathrm{pH} 5.5$ or 7.0. In Fe-containing experiments, ferrihydrite was added to the synthetic medium to a final concentration of $358 \mathrm{mg} / \mathrm{L} \mathrm{Fe}$. The initial cell concentration was adjusted to an optical density (600 nm, $\left.\mathrm{A}_{600}\right)$ of 1.01 (1 cm path length), and growth was measured using a Spectronic GENESYS 5 spectrophotometer (Milton Roy Company, Rochester, NY) with cell-free (filtered) culture medium as reference. In the presence of ferrihydrite cell densities $\left(\mathrm{A}_{600}\right)$ were measured as the difference between the synthetic medium with ferrihydrite plus cells and the synthetic medium with ferrihydrite only. TNT was added to a final concentration of $440 \mu \mathrm{M}$ from an ethanolic stock solution, and the flasks were incubated at $30{ }^{\circ} \mathrm{C}$ with shaking speed of $150 \mathrm{rpm}$. TNT-free control experiments contained pure ethanol $(0.8 \mathrm{~mL}$ of absolute ethanol into $30 \mathrm{~mL}$ of medium). All experiments were set up in triplicate.

Iron synthesis and analysis

Ferrihydrite $\left(\mathrm{Fe}_{2} \mathrm{O}_{3} \cdot \mathrm{H}_{2} \mathrm{O}\right)$ was synthesized by dissolving $3.4 \mathrm{~g}_{\text {of }} \mathrm{FeCl}_{3}$ in $100 \mathrm{~mL}$ of deionized water. $\mathrm{NaOH}$ (6 M) was then added dropwise over $30 \mathrm{~min}$ until a pH of 7.0 was reached (Borch et al. 2005). X-ray diffraction (XRD) analysis showed that two-line ferrihydrite was the major phase after preparation (with possible transitions to six-line ferrihydrite, data not shown). The ferrihydrite suspension was added to a final concentration of $358 \mathrm{mg} / \mathrm{L}$ (as Fe) to the TNT-free or TNTcontaining synthetic medium, and the $\mathrm{pH}$ was adjusted to 5.5 or 7.0 using $0.5 \mathrm{M} \mathrm{HCl}$. Dissolved $\mathrm{Fe}^{2+}$ concentrations were determined after filtration through $0.2 \mu \mathrm{m}$ filters (Spartan 13/0.2 RC; Whatman). Filtered sample $(100 \mu \mathrm{L})$ was added to $400 \mu \mathrm{L}$ of $0.5 \mathrm{M} \mathrm{HCl}$, vortexed for $10 \mathrm{~s}$, and incubated for $1 \mathrm{~h}$ at room temperature. An aliquot $(20 \mu \mathrm{L})$ of this mixture was placed into a well of a 96-well microplate containing $200 \mu \mathrm{L}$ of a $1 \mathrm{~g} / \mathrm{L}$ ferrozine solution in $50 \mathrm{mM}$ HEPES buffer; $\mathrm{pH}$ 7.0), and the absorbance was read at $562 \mathrm{~nm}$ using the Biotek Synergy HT reader. Gen5 software (version 1.02) was used for the data analysis. Total bioavailable iron was estimated as described by Lovley and Phillips (1987). Four hundred microliters of $0.25 \mathrm{M}$ $\mathrm{NH}_{2} \mathrm{OH}-\mathrm{HCI} / 0.25 \mathrm{M} \mathrm{HCl}$ were added to $100 \mu \mathrm{L}$ of unfiltered sample and incubated for 1 hour before ferrozine-based absorbance measurements were conducted as described above (Lovley and Phillips 1987). The cell-free synthetic medium after addition of $0.5 \mathrm{M}$ $\mathrm{HCl}$ or $0.25 \mathrm{M} \mathrm{NH}_{2} \mathrm{OH}-\mathrm{HCI} / 0.25 \mathrm{M} \mathrm{HCl}$ was used as a control. 
Abiotic control experiments

The impact of ferrihydrite on $\mathrm{NO}_{2}^{-}$and $\mathrm{NO}_{3}{ }^{-}$ stability was studied under abiotic conditions in the absence of yeast cells with TNT absent or present. Ferrihydrite suspension in the same amount (as described above) was added to synthetic medium containing either $\mathrm{NaNO}_{2}(300 \mu \mathrm{M})$ or $\mathrm{NaNO}_{3}$ $(300 \mu \mathrm{M}), \mathrm{pH}$ was adjusted to 5.5 and 7.0 using $0.5 \mathrm{M} \mathrm{HCl}$, and the flasks were incubated at $30^{\circ} \mathrm{C}$ with $150 \mathrm{rpm}$ of shaking.

\section{Chromatography}

TNT and its transformation products were determined with a Hewlett Packard 1090 high performance liquid chromatograph as described previously by us (Borch and Gerlach 2004; Ziganshin et al. 2007). Nitrite and nitrate concentrations were analyzed using a Dionex ion chromatograph as described in detail previously (Ziganshin et al. 2007, 2010a). Nitrous oxide $\left(\mathrm{N}_{2} \mathrm{O}\right)$ release was checked using an Agilent 5890 Series II gas chromatograph outfitted with an electron capture detector, a 10-port injection valve and a $1 \mathrm{~cm}^{3}$ sample loop. Two analytical columns (both $183 \mathrm{~cm} \times$ $0.32 \mathrm{~cm}$ OD, packed with Chromosorb 102 80/100 mesh and Porapak-Q 80/100 mesh, respectively) were used in series for gas separation. The temperatures of the column oven and detector were 55 and $360{ }^{\circ} \mathrm{C}$, respectively. The carrier gas was a commercial ultrahigh purity $\mathrm{N}_{2}$, which was further purified through Molecular Sieve 5A, activated charcoal and an oxygen scrubber. To promote ionization, high purity $\mathrm{CO}_{2}$ was introduced to the gas stream just before the detector at approximately $2 \%$ of the carrier gas flow. Both the carrier and backflushing flows were approximately $28 \mathrm{~mL} / \mathrm{min}$. For each sample $10 \mathrm{~mL}$ of the medium were collected into a $20 \mathrm{cc}$ polypropylene syringe, to which $10 \mathrm{~mL}$ of purified $\mathrm{N}_{2}$ carrier were added. The syringe contents were equilibrated at $21.5^{\circ} \mathrm{C}$ in a shaking incubator at $100 \mathrm{rpm}$ for $30 \mathrm{~min}$ before $1 \mathrm{~mL}$ of the gaseous phase was injected into the GC.

\section{Electron spin resonance (ESR) spectroscopy}

Nitric oxide (NO) production during TNT biodegradation was confirmed after adding $10 \mu \mathrm{L}$ of $5.8 \mathrm{mM}$ DETC and $10 \mu \mathrm{L}$ of $2.6 \mathrm{mM} \mathrm{FeSO}_{4}$ to $100 \mu \mathrm{L}$ of cellcontaining medium. The mixture was incubated for
$30 \mathrm{~min}$ at $37^{\circ} \mathrm{C}$, cooled on ice for $1 \mathrm{~min}$, and added to $200 \mu \mathrm{L}$ of fresh, water-saturated ethylacetate. The mixture was intensively mixed for $3 \mathrm{~min}$ and centrifuged at $6,000 \times \mathrm{g}$ for $8 \mathrm{~min}$. After the organic phase was transferred to quartz tubes with an inner diameter of $1 \mathrm{~mm}$ (Sigma-Aldrich, Germany), ESR spectra were registered at room temperature using a Bruker ESP 300 Electron Spin Resonance spectrometer (Bruker, Germany). The experimental parameters were as follows: Microwave frequency $9.68 \mathrm{GHz}$, microwave power $100 \mathrm{~mW}$ and modulation amplitude $4.0 \mathrm{G}$ (Fujii and Berliner 1999; Vanin et al. 2000). TNT-free medium with yeast cells was used as a control.

\section{Scanning electron microscopy}

In order to visualize the association of yeast cell surfaces with iron minerals, Y. lipolytica AN-L15 cell suspensions were removed from the growth medium under different cultivation conditions at 0,10 , and $24 \mathrm{~h}$. Yeast cell suspensions were washed with deionized water, pipetted onto a glass microscopy slide, dried for 15-20 min and fixed in $2 \%$ paraformaldehyde $/ 2.5 \%$ glutaraldehyde in $0.08 \mathrm{M}$ PIPES buffer ( $\mathrm{pH}$ 6.8) for $12-15 \mathrm{~h}$ at room temperature. The slides were briefly rinsed with deionized water (4 times), and dehydration of cells was carried out using a series of ethanol-water solutions $(25,50,75,95,100 \%)$ (each step for $5 \mathrm{~min}$ ). After iridium coating, the obtained specimens were observed using a Zeiss Supra 55VP scanning electron microscope (Germany). High resolution images were acquired using an accelerating voltage of $1.0 \mathrm{kV}$ at a working distance of $3-5 \mathrm{~mm}$.

\section{Results}

The aim of this research work was to assess the effect of ferrihydrite on TNT transformation by $Y$. lipolytica strain AN-L15. According to published literature (e.g. Morgan and Lahav 2007), pH plays a crucial role in iron transformation, therefore, TNT transformation was monitored at different initial $\mathrm{pH}$ values.

TNT transformation by $Y$. lipolytica in the presence of ferrihydrite at an initial $\mathrm{pH}$ of 5.5

An initial $\mathrm{pH}$ of 5.5 has been described to be ideal for growth of $Y$. lipolytica (Ziganshin et al. 2007). 
Hence, the influence of ferrihydrite on TNT transformation by $Y$. lipolytica was initially evaluated under these conditions. Independently of the presence of ferrihydrite, the lag phase of $Y$. lipolytica growth was extended in TNT-containing systems compared to TNT-free treatments (Figs. 1a, 2a). A cell density $\left(\mathrm{A}_{600}\right)$ of 3.1 was observed after $14 \mathrm{~h}$ of cultivation in $\mathrm{Fe}$ - and TNT-containing systems (Fig. 1a). In the absence of ferrihydrite similar growth was observed with an $\mathrm{A}_{600}$ of 2.9 reached after $14 \mathrm{~h}$ of cultivation in TNT-containing treatments (Fig. 2a). Our previous work showed that $Y$. lipolytica produces organic acids (citrate and pyruvate) during consumption of glucose and ethanol (Ziganshin et al. 2010a). The addition of ferrihydrite to the medium led to a delay in $\mathrm{pH}$ decrease, which could be attributed to an increase in buffer capacity or a decreased rate of organic acid production by the yeast cells in the presence of ferrihydrite. However, despite this increase in buffer capacity or reduced rate of proton generation, $\mathrm{pH}$ values after $24 \mathrm{~h}$ were similar for ferrihydrite-containing and ferrihydrite-free treatments (Figs. 1a, 2a).

Recently we demonstrated the influence of the

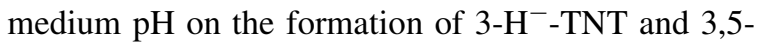
$2 \mathrm{H}^{-}$-TNT $\cdot \mathrm{H}^{+}$complexes from TNT by $Y$. lipolytica strain AN-L15 as well as their subsequent transformation and destruction (Ziganshin et al. 2010a). The research described herein demonstrated that the presence of ferrihydrite in the culture medium resulted in the accumulation of the same metabolites; however, the presence of ferrihydrite decreased the rate of TNT biotransformation.

The main pathway of TNT biotransformation in the presence of ferrihydrite occurred via aromatic ring reduction and led to accumulation of $3-\mathrm{H}^{-}$-TNT followed by the formation of 2,4-DNT and $3,5-2 \mathrm{H}^{-}$TNT $\cdot \mathrm{H}^{+}$isomers. The maximum $3-\mathrm{H}^{-}$-TNT concentration in ferrihydrite-containing medium was detected after $6 \mathrm{~h}$ and reached $272 \pm 21 \mu \mathrm{M}$, while the maximum amount of $3-\mathrm{H}^{-}$-TNT in $\mathrm{Fe}$-free experiments was observed after $4 \mathrm{~h}$ and reached the level of $285 \pm 18 \mu \mathrm{M}$ (Figs. 1b, 2b). Another product of aromatic ring reduction, $1-\mathrm{H}^{-}-\mathrm{TNT}$, was also observed in the presence of ferrihydrite.

Continued cultivation was accompanied by $3-\mathrm{H}^{-}$TNT conversion to 2,4-DNT and 3,5-2 $\mathrm{H}^{-}$-TNT. $\mathrm{H}^{+}$ complexes in both treatments. However, transformation of $3-\mathrm{H}^{-}$-TNT in the absence of ferrihydrite resulted in accumulation of more 2,4-DNT; $79 \mu \mathrm{M}$ in
Fe-free systems compared to $13 \mu \mathrm{M}$ of 2,4-DNT in Fe-containing systems (Figs. 1c, 2c).

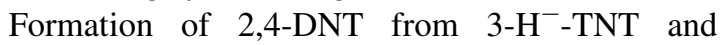
destruction of $3,5-2 \mathrm{H}^{-}-\mathrm{TNT} \cdot \mathrm{H}^{+}$was accompanied by the accumulation of $\mathrm{NO}_{2}{ }^{-}$with subsequent conversion to $\mathrm{NO}_{3}{ }^{-}$and $\mathrm{NO}$ under acidic conditions. After $8 \mathrm{~h}, 65 \mu \mathrm{M}$ of $\mathrm{NO}_{2}{ }^{-}$had been released in the presence of $\mathrm{Fe}$. The $\mathrm{NO}_{2}{ }^{-}$was further converted into $\mathrm{NO}_{3}{ }^{-}$and $\mathrm{NO}$ after the medium $\mathrm{pH}$ decreased below approximately 4.5 as observed in Ziganshin et al. (2010a). Transformation of $3,5-2 \mathrm{H}^{-}-\mathrm{TNT} \cdot \mathrm{H}^{+}$complexes under acidic conditions occurred simultaneously with $\mathrm{NO}_{3}{ }^{-}$accumulation, and a maximum concentration of $156 \mu \mathrm{M} \mathrm{NO}_{3}{ }^{-}$was reached after $24 \mathrm{~h}$ (Fig. 1c). In the absence of ferrihydrite maximum amounts of $\mathrm{NO}_{2}{ }^{-}(44 \mu \mathrm{M})$ and $\mathrm{NO}_{3}{ }^{-}(143 \mu \mathrm{M})$ were observed after 3 and $14 \mathrm{~h}$ of yeast cell growth, respectively (Fig. 2c).

Previously, we hypothesized that nitric oxide (NO) was produced during TNT degradation by $Y$. lipolytica (Ziganshin et al. 2010a). Here, we used ESR spectroscopy to confirm the presence of NO (Fig. 3). The ESR spectra agree with spectra obtained in other work focused on NO detection (Fujii and Berliner 1999; Ueno et al. 2002) and clearly demonstrate that NO is released over the course of TNT transformation (Fig. 3b, d). We hypothesize that NO is generated during the disproportionation of $\mathrm{NO}_{2}{ }^{-}$resulting in the production of $\mathrm{NO}$ and $\mathrm{NO}_{3}{ }^{-}$under acidic conditions. Control experiments in the absence of TNT did not reveal production of NO (Fig. 3a, c).

In our previous work (Ziganshin et al. 2010a), we found that $Y$. lipolytica AN-L15 was unable to use $\mathrm{NO}_{2}{ }^{-}$or $\mathrm{NO}_{3}{ }^{-}$as the sole source of nitrogen for growth and that the process of $\mathrm{NO}_{2}{ }^{-}$oxidation to $\mathrm{NO}_{3}{ }^{-}$was (i) $\mathrm{pH}$-dependent and (ii) accelerated in the presence of strain AN-L15. In this study similar control experiments were performed to evaluate the possibility of the abiotic transformation of $\mathrm{NO}_{2}{ }^{-}$or $\mathrm{NO}_{3}{ }^{-}$in the presence of ferrihydrite. The addition of $\mathrm{NaNO}_{2}$ or $\mathrm{NaNO}_{3}(300 \mu \mathrm{M})$ to ferrihydrite-containing medium at $\mathrm{pH} 5.5$ or 7.0 in the absence of yeast cells did not result in any transformations over the course of the experiments, indicating the relative stability of $\mathrm{NO}_{2}{ }^{-}$or $\mathrm{NO}_{3}{ }^{-}$under these conditions (data not shown).

TNT transformation via nitro group reduction occurred as well and resulted in the formation of HADNTs. In the presence of ferrihydrite 40 and 
Fig. 1 a Growth $\left(\mathrm{A}_{600}\right)$ of $Y$. lipolytica AN-L15 and subsequent $\mathrm{pH}$ change in the presence of ferrihydrite (initial medium $\mathrm{pH}$ 5.5). b, c Formation of metabolites during TNT transformation by $Y$. lipolytica AN-L15 in the presence of ferrihydrite. Concentrations of TNT, 3-H ${ }^{-}$-TNT, HADNTs, ADNTs, 2,4-DNT, $\mathrm{NO}_{2}{ }^{-}$, and $\mathrm{NO}_{3}{ }^{-}$are expressed in $\mu \mathrm{M}$. $1-\mathrm{H}^{-}$-TNT (peak area at $476 \mathrm{~nm}$ ) and sum of mono- and dihydride complexes related to $3-\mathrm{H}^{-}$TNT are expressed as the sum of the absorbance peak areas at $476 \mathrm{~nm}$. d Fe $\mathrm{Fe}^{2+}$ formation in the presence of ferrihydrite. Error bars represent the standard deviation of triplicate experiments
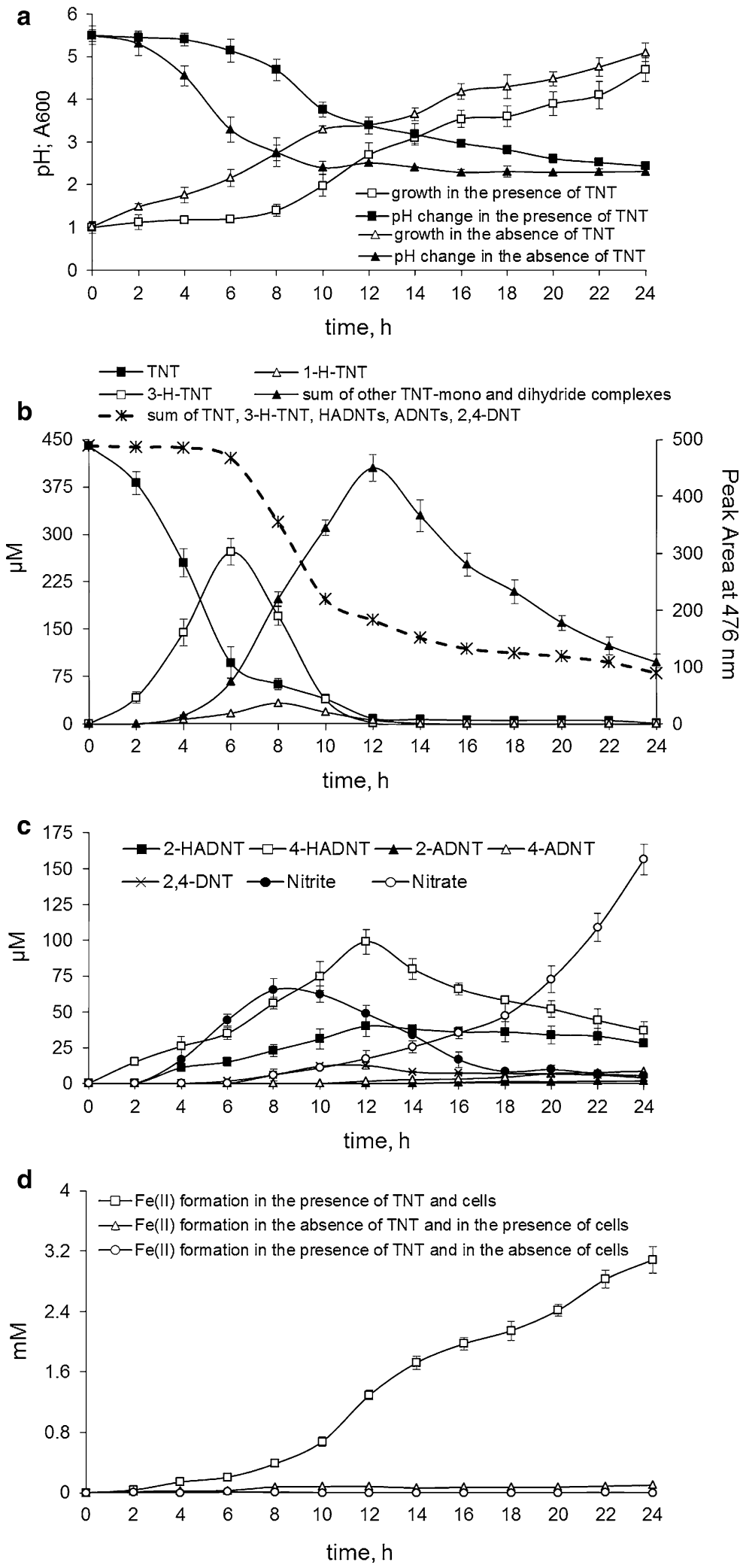
Fig. 2 a Growth $\left(\mathrm{A}_{600}\right)$ of $Y$. lipolytica AN-L15 and subsequent $\mathrm{pH}$ change in the absence of ferrihydrite (initial medium $\mathrm{pH}$ 5.5). b, c Formation of metabolites during TNT transformation by $Y$. lipolytica AN-L15 in the absence of ferrihydrite. Concentrations of TNT, 3-H ${ }^{-}$-TNT, HADNTs, 2,4DNT, $\mathrm{NO}_{2}{ }^{-}$, and $\mathrm{NO}_{3}{ }^{-}$are expressed in $\mu \mathrm{M}$. 1- $\mathrm{H}^{-}$-TNT (peak area at $476 \mathrm{~nm}$ ) and sum of mono- and dihydride complexes related to $3-\mathrm{H}^{-}$TNT are expressed as the sum of the absorbance peak areas at $476 \mathrm{~nm}$. Error bars represent the standard deviation of triplicate experiments
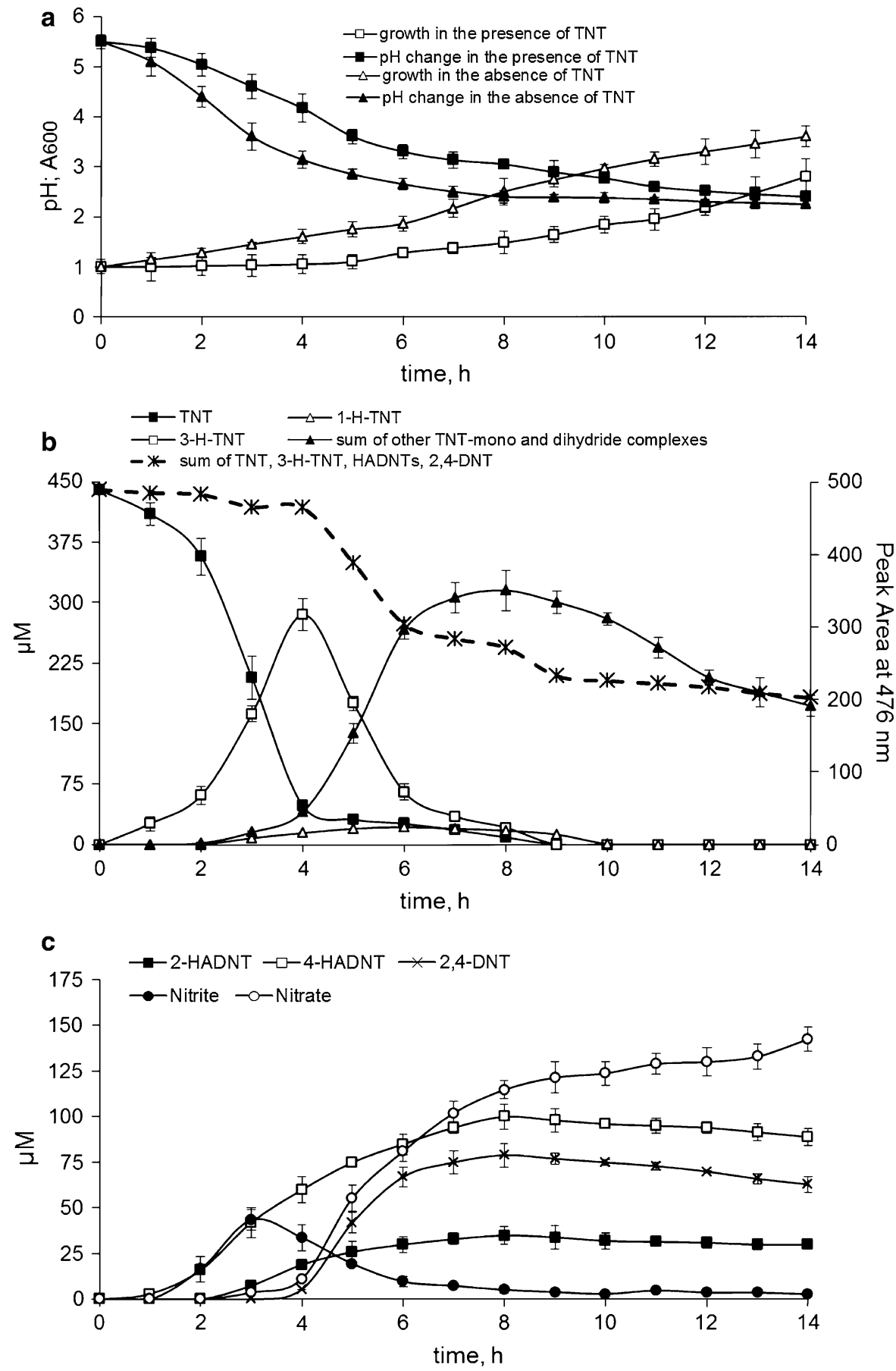

$99 \mu \mathrm{M}$ of 2-HADNT and 4-HADNT, respectively, were produced after $12 \mathrm{~h}$, and similar results were obtained after $8 \mathrm{~h}$ of yeast growth in Fe-free medium (35 and $100 \mu \mathrm{M}$ of 2-HADNT and 4-HADNT, accordingly; Figs. 1c and 2c). Continued conversion of 4-HADNT by $Y$. lipolytica in the presence of $\mathrm{Fe}$ resulted in its decrease with accumulation of small amounts of 4-ADNT. In Fe-free studies 4-HADNT concentrations decreased more slowly and no ADNT formation was observed (Figs. 1c, 2c).

The sum of all quantifiable carbon containing TNT metabolites over the course of the experiments is 


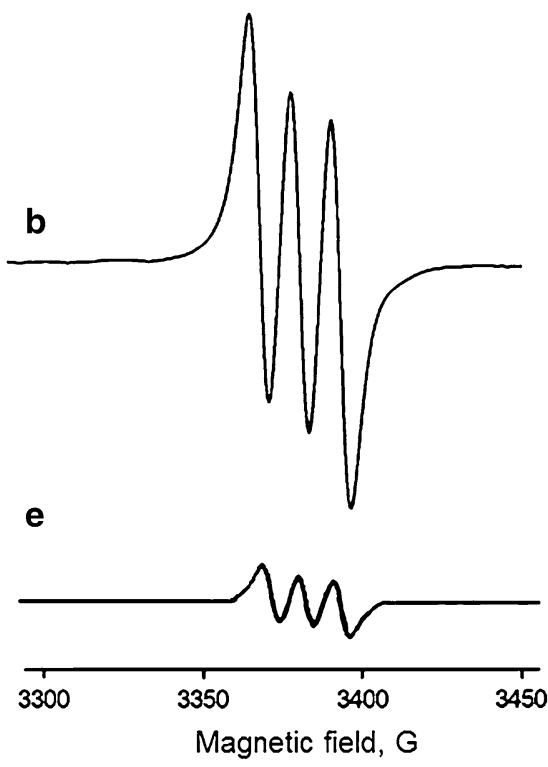

Fig. 3 ESR spectra of (DETC) $)_{2}-\mathrm{Fe}(\mathrm{II})-\mathrm{NO}$ obtained during the experiments. a TNT- and ferrihydrite-free synthetic medium with $Y$. lipolytica AN-L15 cells (control). b After $5 \mathrm{~h}$ of $Y$. lipolytica AN-L15 growth in the presence of TNT and in the absence of ferrihydrite (initial $\mathrm{pH} 5.5$ ), indicating $\mathrm{NO}$ release during TNT degradation. c TNT-free and ferrihydrite-containing synthetic medium with Y. lipolytica AN-L15 cells (control).

indicated with a thick dashed line in Figs. $1 \mathrm{~b}$ and $2 \mathrm{~b}$. Due to the lack of stability, TNT-monohydride and dihydride complex standards are not available. We were able to estimate the concentrations of $3-\mathrm{H}^{-}-\mathrm{TNT}$ based on an approach outlined in Ziganshin et al. (2007) but were unable to determine the concentrations of other TNT-hydride complexes. Hence, we were unable to account for all carbon containing metabolites once TNT-mono- and dihydride complexes were produced in the systems. It appears though that most of $3-\mathrm{H}^{-}$-TNT was transformed into other TNT-mono- and dihydride complexes after 6 and $4 \mathrm{~h}$ for Figs. $1 b$ and $2 b$, respectively.

As shown in Fig. 1d, $\mathrm{Fe}^{3+}$ (as ferrihydrite) added to cell-free and TNT-containing medium did not undergo reduction to $\mathrm{Fe}^{2+}$. Only low amounts of $\mathrm{Fe}^{2+}(0.1 \mathrm{mM}$ after $24 \mathrm{~h}$ ) were generated in the presence of yeast cells but absence of TNT. However, significant $\mathrm{Fe}^{2+}$ accumulation was observed in the presence of TNT and yeast cells. The maximum concentration of $\mathrm{Fe}^{2+}$
C

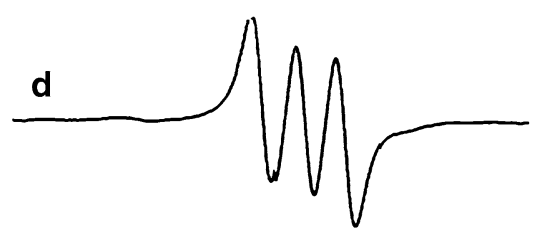

$\begin{array}{llrl}3300 & 3350 & 3400 & 3450 \\ & \text { Magnetic field, } G & \end{array}$

d After $8 \mathrm{~h}$ of $Y$. lipolytica AN-L15 growth in the presence of TNT and ferrihydrite (initial $\mathrm{pH} 5.5$ ), indicating NO release during TNT degradation. e (DETC) ${ }_{2}$-Fe(II) with the NO donor SNAP $(10 \mu \mathrm{M})$. Spectra were recorded at room temperature with microwave frequency of $9.68 \mathrm{GHz}$, microwave power of $100 \mathrm{~mW}$ and modulation amplitude of $4 \mathrm{G}$

produced in the presence of TNT reached $3.1 \mathrm{mM}$ within $24 \mathrm{~h}$ of inoculation with strain AN-L15.

TNT transformation by $Y$. lipolytica in the presence of ferrihydrite at an initial $\mathrm{pH}$ of 7.0

In order to estimate the impact of ferrihydrite on the rate and pathway of TNT transformation by $Y$. lipolytica under initially $\mathrm{pH}$ neutral conditions, a TNT transformation study was conducted with an initial $\mathrm{pH}$ of 7.0. As observed in the $\mathrm{pH} 5.5$ treatments, yeast growth in TNT-containing medium was delayed compared to TNT-free treatments (Figs. 4a, S1a, Supplementary material). As observed for the $\mathrm{pH} 5.5$ systems (Figs. 1a, 2a), the presence of ferrihydrite and TNT resulted in a slower decrease in pH (Figs. 4a, S1a) presumably due to $\mathrm{pH}$ buffering by ferrihydrite or reduced organic acid production in the presence of TNT and ferrihydrite (Figs. 4a, S1a). 
As observed in $\mathrm{pH} 5.5$ treatments, TNT transformation occurred via aromatic ring reduction as well as through nitro group reduction. TNT-monohydride (e.g. 3- $\mathrm{H}^{-}$-TNT, $1-\mathrm{H}^{-}-\mathrm{TNT}$ ) and -dihydride complexes formed successively during the aromatic ring reduction of TNT regardless of the presence of ferrihydrite (Figs. 4b, S1b). In Fe-containing systems, $294 \pm 20 \mu \mathrm{M}$ of $3-\mathrm{H}^{-}$-TNT had accumulated after 10 h. $3-\mathrm{H}^{-}$-TNT was further transformed to several metabolites including 2,4-DNT $(14 \mu \mathrm{M})$ and TNTdihydride isomers (Figs. 4b, c). In addition, after $22 \mathrm{~h}$, $82 \mu \mathrm{M}$ of $\mathrm{NO}_{2}{ }^{-}$were detected, which were oxidized to $\mathrm{NO}_{3}{ }^{-}$after the $\mathrm{pH}$ value of the culture medium had dropped below approximately 4.5 . The maximum amount of $\mathrm{NO}_{3}{ }^{-}$detected was $38 \mu \mathrm{M}$ after $24 \mathrm{~h}$ (Fig. 4c) and its concentration increased thereafter (data not shown). Interestingly, TNT was never completely reduced by $Y$. lipolytica in the presence of ferrihydrite and, after $16 \mathrm{~h}$, a temporary increase in TNT concentration was observed (Fig. 4b). TNT can be re-formed from $3-\mathrm{H}^{-}$-TNT via a disproportionation reaction resulting in the production of TNT-dihydride complexes and TNT as described by us previously (Ziganshin et al. 2007).

In the absence of ferrihydrite, TNT biotransformation by $Y$. lipolytica occurred at higher rates with the detection of the same metabolites. Maximum amounts

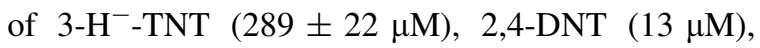
$\mathrm{NO}_{2}{ }^{-}(101 \mu \mathrm{M})$, and $\mathrm{NO}_{3}{ }^{-}(62 \mu \mathrm{M})$ were observed after $5,11,12$, and $14 \mathrm{~h}$, respectively (Figs. S1b, c). Results in the absence of ferrihydrite are similar to our recent work (Ziganshin et al. 2010a) with the differences (i.e. higher rate of TNT transformation) attributed to the higher initial cell concentration used in this study $\left(\mathrm{A}_{600}\right.$ of 1.0 compared to $\mathrm{A}_{600}$ of 0.2 in Ziganshin et al. 2010a). As in the pH 5.5 treatments NO production from TNT was also observed (data not shown).

A small amount of TNT was converted to HADNTs and ADNTs via nitro group reduction and maximum concentrations of 50 and $83 \mu \mathrm{M}$ for 2-HADNT and 4-HADNT, respectively, were observed in the presence of ferrihydrite after $22 \mathrm{~h}$ (Fig. 4c) compared to 49 and $96 \mu \mathrm{M}$ in ferrihydrite-free systems after $11 \mathrm{~h}$ (Fig. S1c). After 10 h, 2-HADNT and 4-HADNT had started to convert into amino-dinitrotoluenes in ferrihydrite-containing systems with accumulations of 2 and $10 \mu \mathrm{M}$ of 2-ADNT and 4-ADNT, respectively after $24 \mathrm{~h}$ (Fig. 4c). In Fe-free systems, only $2 \mu \mathrm{M}$ of
4-ADNT had accumulated after $14 \mathrm{~h}$ of yeast growth (Fig. S1c).

As observed in the $\mathrm{pH} 5.5$ experiments (Figs. 1,2), the sum of all quantifiable carbon containing TNT metabolites over the course of the experiments, indicated with thick dashed lines in Figs. $4 \mathrm{~b}$ and $\mathrm{S} 1 \mathrm{~b}$, decreases to well below $100 \%$ once $3-\mathrm{H}^{-}$-TNT is being converted to TNT-mono- and dihydride complexes (after approximately $6 \mathrm{~h}$ ). It was indicated earlier that this is due to a lack of available TNTmono- and dihydride complex standards.

As observed in the $\mathrm{pH} 7.0$ systems, the gradual reduction of $\mathrm{Fe}^{3+}$ was detected in TNT-containing medium in the presence of ferrihydrite and yeast cells (Fig. 4d) though to a lesser extent than in the pH 5.5 experiments (Fig. 1d). After $24 \mathrm{~h}$, the concentration of $\mathrm{Fe}^{2+}$ reached $1.5 \mathrm{mM}$ and continued to increase thereafter (data not shown). Just as observed in the pH 5.5 systems, only low amounts of $\mathrm{Fe}^{2+}$ were produced in the absence of TNT ( $0.2 \mathrm{mM}$ within $24 \mathrm{~h})$ and $\mathrm{Fe}^{2+}$ production was not observed in cell-free systems (Fig. 4d). $\mathrm{Fe}^{3+}$ reduction appears to be promoted at $\mathrm{pH}$ of 5.5 compared to $\mathrm{pH} 7.0$, which correlates with the higher solubility of ferrihydrite under acidic conditions (Cudennec and Lecerf 2006).

\section{Discussion}

In our previous studies we reported that $Y$. lipolytica AN-L15 transforms TNT via aromatic ring reduction as the key pathway leading to destruction of the parent compound as well as through nitro group reduction resulting in accumulation of HADNTs and ADNTs in Fe-free growth medium (Ziganshin et al. 2007, 2010a). The work presented here illustrates the biodegradation of TNT during growth of $Y$. lipolytica in the presence of ferrihydrite as a proxy for Fe-containing minerals in the environment. Fig. 5 shows a schematic diagram of possible pathways of TNT transformation in the presence of Y. lipolytica AN-L15.

As described by us previously (Ziganshin et al. 2007, 2010a), TNT transformation by $Y$. lipolytica can occur (a) via aromatic ring reduction to produce TNThydride complexes, which are transformed further to dinitrotoluenes and inorganic nitrogen species including nitrite and nitrate; and (b) via nitro group reduction resulting in the production of hydroxylamino-dinitrotoluenes and amino-dinitrotoluenes, which might be 
Fig. 4 a Growth $\left(\mathrm{A}_{600}\right)$ of $Y$. lipolytica AN-L15 and subsequent $\mathrm{pH}$ change in the presence of ferrihydrite (initial medium $\mathrm{pH}$ 7.0). b, c Formation of metabolites during TNT transformation by $Y$. lipolytica AN-L15 in the presence of ferrihydrite. Concentrations of TNT, 3-H- ${ }^{-}$TNT, HADNTs, ADNTs, 2,4-DNT, $\mathrm{NO}_{2}{ }^{-}$, and $\mathrm{NO}_{3}{ }^{-}$are expressed in $\mu \mathrm{M}$. $1-\mathrm{H}^{-}$-TNT (peak area at $476 \mathrm{~nm}$ ) and sum of mono- and dihydride complexes related to $3-\mathrm{H}^{-}$TNT are expressed as the sum of the absorbance peak areas at $476 \mathrm{~nm}$. d Fe $\mathrm{Fe}^{2+}$ formation in the presence of ferrihydrite. Error bars represent the standard deviation of triplicate experiments
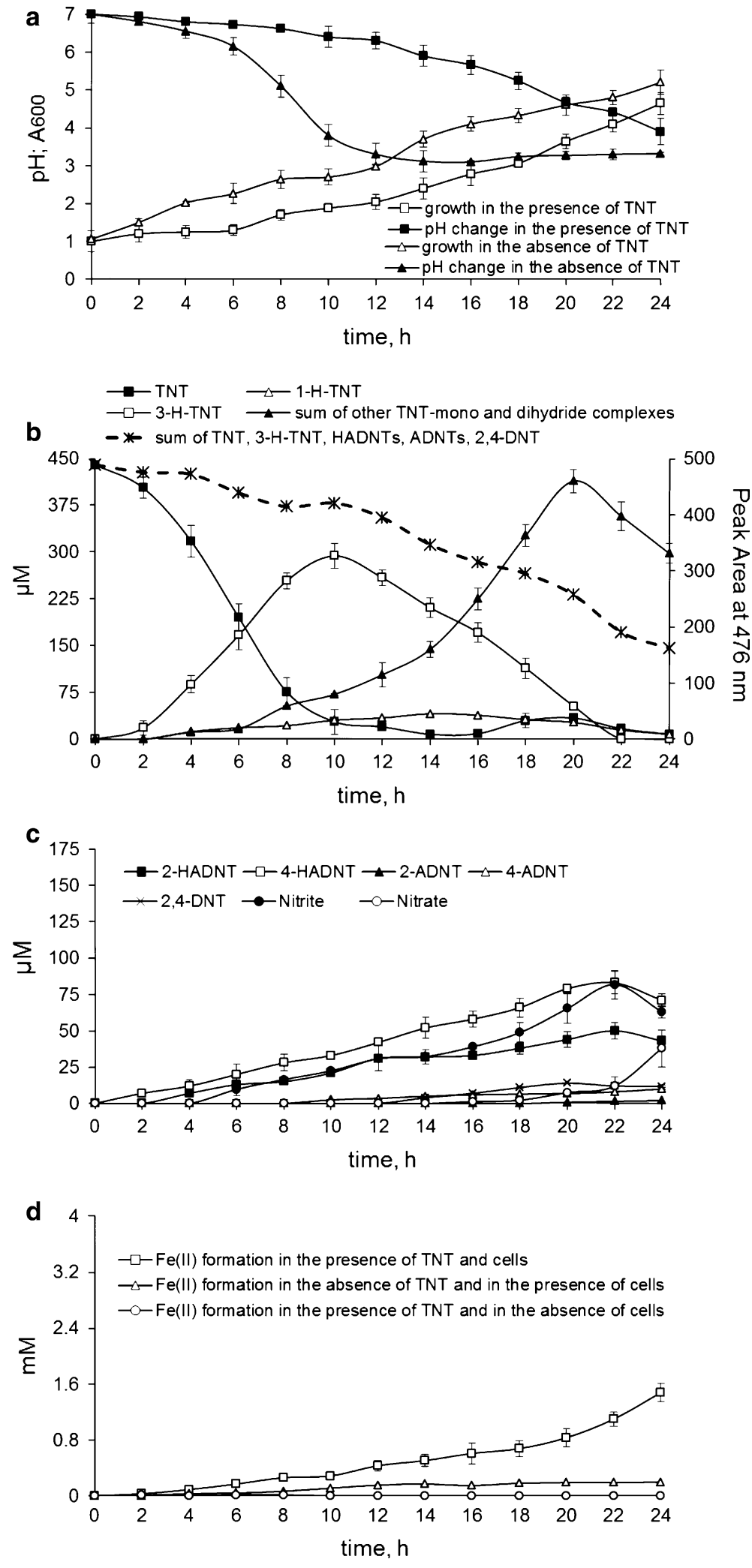


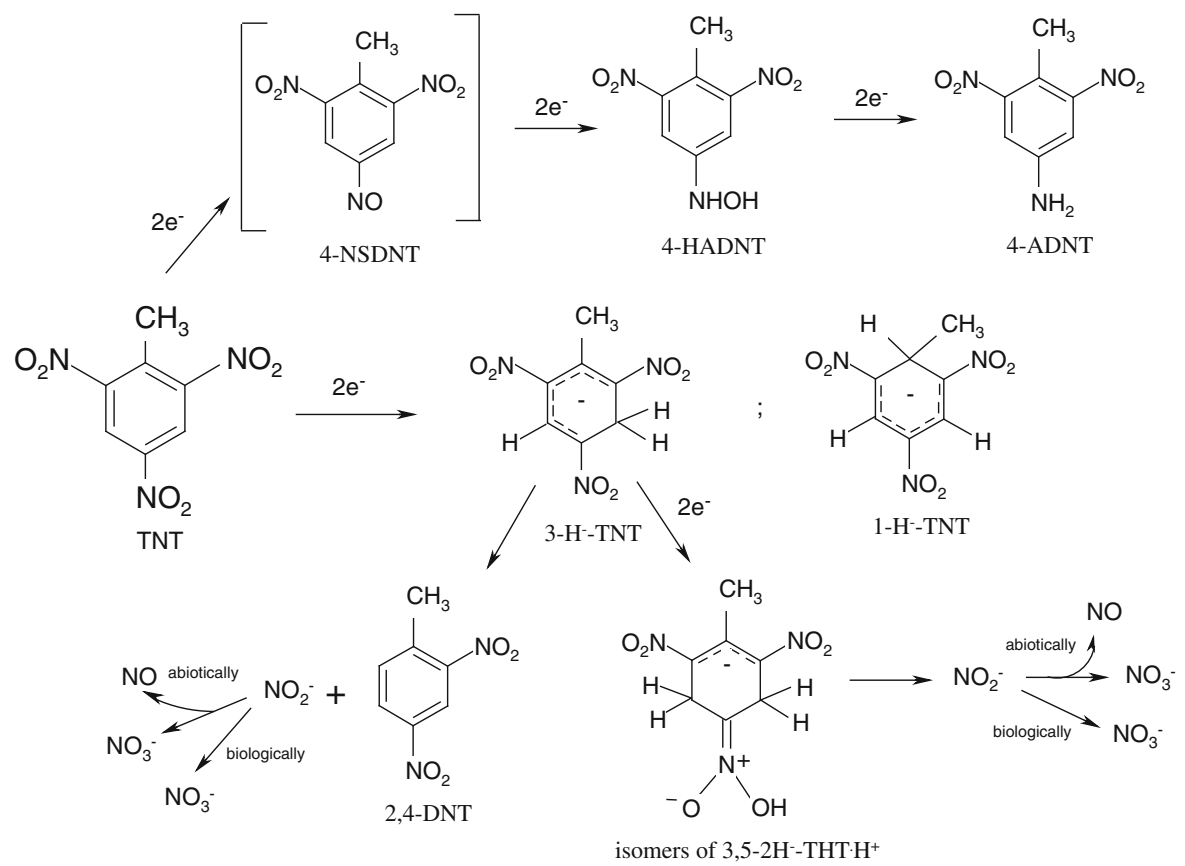

Fig. 5 Schematic illustrating possible pathways of TNT transformation in the presence/absence of ferrihydrite and in the presence of $Y$. lipolytica AN-L15. Nitroso-dinitrotoluenes (NSDNT) are shown as possible intermediates during TNT nitro group reduction, although they were not detected in this work. Only the para-substituted metabolites are shown (4-NSDNT, 4-HADNT, 4-ADNT). Ortho-substituted metabolites (2-HADNT, 2-ADNT) were also detected but are not pictured. Hydroxylamino-mononitrotoluenes (HAMNT) are not shown in the diagram since they were detected at very low levels only.

transformed further. In the presence of ferrihydrite, $\mathrm{Fe}^{3+}$ reduction occurs and might be due to enzyme activity or due to chemical reduction of ferric iron by other microbially produced compounds formed during TNT transformation.

Transformation of TNT by microorganisms in the presence of Fe-bearing mineral surfaces has been investigated previously (e.g. Hofstetter et al. 1999; Borch et al. 2005; Nefso et al. 2005; Eyers et al. 2008); however, most microbes were observed to convert TNT to amino derivatives, which accumulated without further transformation. Only Eyers et al. (2008) demonstrated TNT denitration by $P$. aeruginosa ESA-5 in the presence of ferrihydrite under anoxic conditions with significant $\mathrm{NO}_{2}{ }^{-}$release. This is the first report demonstrating the influence of ferrihydrite on the pathway and rate of TNT transformation with concomitant $\mathrm{NO}_{2}{ }^{-}, \mathrm{NO}_{3}{ }^{-}$and $\mathrm{NO}$ production.

The most important aromatic ring reduction products are shown:

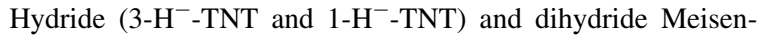
heimer complexes (latter indicated by one possible isomer) as well as 2,4-dinitrotoluene (2,4-DNT), nitrite, nitrate and nitric oxide. In addition possible oxidation-reduction reactions involving $\mathrm{Fe}^{3+}$ and $\mathrm{Fe}^{2+}$ (e.g. with partially reduced TNT nitro group reduction products or reactive oxygen species) are not illustrated in the figure. Compound conversions and electron flows are not meant to be quantitative

We demonstrated that TNT was stable in the presence of ferrihydrite under abiotic conditions. In biotic experiments, the maximum concentrations of TNT-mono- and dihydride complexes observed did not vary significantly regardless of the presence of ferrihydrite. However, the presence of ferrihydrite in the medium resulted in a slower decrease of the medium $\mathrm{pH}$ and a decreased rate of $3-\mathrm{H}^{-}$-TNT and $1-\mathrm{H}^{-}-\mathrm{TNT}$ formation as well as slower subsequent conversion to TNT-dihydride complexes. In the absence of ferrihydrite more 2,4-DNT formation was observed than in the presence of ferrihydrite during $3-\mathrm{H}^{-}$-TNT degradation. The maximum amounts of 2-HADNT and 4-HADNT detected in both, the presence and absence of ferrihydrite, were at the same level with the dominance of metabolites at the para position (as previously described by Borch et al. 2005). Continued reduction of HADNTs to ADNTs was observed in the 
presence of ferrihydrite, which is in line with previous observations by Borch et al. (2005) who reported an increased rate of TNT to ADNT conversion in the presence of ferrihydrite by Cellulomonas sp. strain ES6 under fermentative conditions. Hence, an enhancement of TNT transformation by aerobic yeast cells had been hypothesized by us. However, this study indicates that the presence of ferrihydrite slightly reduces the rate of TNT transformation by aerobically grown Y. lipolytica AN-L15 cells. Thus, the hypothesis that ferrihydrite would enhance the transformation rate of TNT was not confirmed.

Our earlier studies also demonstrated that Y. lipolytica AN-L15 can excrete organic acids into the medium resulting in a decrease of the medium $\mathrm{pH}$ (Ziganshin et al. 2010a). In the presence of TNT and ferrihydrite $Y$. lipolytica was not able to acidify the medium as quickly as in the presence of TNT alone. This is very likely due to an increased buffer capacity contributed by ferrihydrite, which in turn led to a slower rate of TNT biodegradation by $Y$. lipolytica.

Increased $\mathrm{Fe}^{3+}$ reduction was found in the presence of TNT and yeast cells compared to TNT-free treatments. Treatments with an initial $\mathrm{pH}$ of 5.5 showed higher $\mathrm{Fe}^{2+}$ concentrations in the presence of TNT and yeast cells than $\mathrm{pH} 7.0$ experiments. Since the solubility of ferrihydrite is higher under acidic conditions (Cudennec and Lecerf 2006), $\mathrm{Fe}^{3+}$ reduction might be accelerated at lower $\mathrm{pH}$ values. One possible mechanism of $\mathrm{Fe}^{2+}$ production is the induction of enzymes by TNT, its metabolites or other organics; if these enzymes possess $\mathrm{Fe}^{3+}$ reduction activity, $\mathrm{Fe}^{2+}$ production could be observed. Another pathway of $\mathrm{Fe}^{2+}$ generation is the accumulation of metabolites from TNT-hydride complexes capable of reducing $\mathrm{Fe}^{3+}$ chemically. A similar effect was demonstrated previously for other organic compounds (Aguiar et al. 2006).

Yet another conceivable mechanism of $\mathrm{Fe}^{2+}$ generation, involving the electron transfer from $3-\mathrm{H}^{-}$TNT and $3,5-2 \mathrm{H}^{-}-\mathrm{TNT} \cdot \mathrm{H}^{+}$isomers to $\mathrm{Fe}^{3+}$, was ruled out. TNT-hydride complexes were prepared by chemical reduction of TNT with $\mathrm{NaBH}_{4}$ in acetonitrile solution as described previously by French et al. (1998). However, the addition of these hydride complexes to ferrihydrite at $\mathrm{pH} 5.5$ or $7.0 \mathrm{did}$ not result in observable $\mathrm{Fe}^{2+}$ production (data not shown).

While it is possible that part of the formed Fe(II) was oxidized back to $\mathrm{Fe}$ (III) by molecular oxygen
(Morgan and Lahav 2007), it is also possible that $\mathrm{Fe}(\mathrm{II})$ was involved in the abiotic reduction of nitro groups (Hofstetter et al. 1999; Nefso et al. 2005). While this reaction would theoretically result in increased concentrations of nitro group conversion products it might have not been observable here since they might have reacted with large biomolecules as described by Leung et al. (1995). Alternatively, the nitro group conversion products might have undergone further degradation with $\mathrm{NH}_{4}{ }^{+}$release as suggested by Vorbeck et al. (1998).

This is the first time ESR spectroscopy was used to detect NO as a metabolite of TNT degradation by $Y$. lipolytica AN-L15. The possible pathway of its formation is the disproportionation of nitrous acid (from nitrite released during TNT-hydride complex transformation) at acidic $\mathrm{pH}$ values as described by Cai et al. (2001). The associated production of volatile nitrogen oxides led to a net loss of nitrogen from the experimental systems. In abiotic experiments with and without TNT, the stability of $\mathrm{NO}_{2}{ }^{-}$or $\mathrm{NO}_{3}{ }^{-}$in the presence of ferrihydrite was demonstrated in oxygenated synthetic medium at $\mathrm{pH} 5.5$ and 7.0. Abiotic $\mathrm{NO}_{2}{ }^{-}$conversion to $\mathrm{NO}_{3}{ }^{-}$was observed, however, at $\mathrm{pH}$ values lower than 4.5 as previously reported by us for Y. lipolytica AN-L15 (Ziganshin et al. 2010a). Here, we demonstrated that $\mathrm{NO}_{2}{ }^{-}$released during the biodegradation of TNT-hydride complexes was further converted to $\mathrm{NO}_{3}{ }^{-}$biologically and to $\mathrm{NO}_{3}{ }^{-}$and $\mathrm{NO}$ abiotically, independently of the presence of ferrihydrite once the $\mathrm{pH}$ had decreased.

No statistically reliable $\mathrm{N}_{2} \mathrm{O}$ was detected in our systems, even though its production from $\mathrm{NO}_{2}{ }^{-}$in the presence of iron oxides had been reported previously (Coby and Picardal 2005). Coby and Picardal (2005) demonstrated enhanced $\mathrm{N}_{2} \mathrm{O}$ production after abiotic reactions between $\mathrm{Fe}^{2+}$, sorbed to goethite or to cell surfaces, and $\mathrm{NO}_{2}{ }^{-}$compared to reactions between aqueous $\mathrm{Fe}^{2+}$ and $\mathrm{NO}_{2}{ }^{-}$. Using electron microscopy Coby and Picardal (2005) showed Fe(hydr)oxide coating on cells treated with $\mathrm{Fe}^{2+}$ and $\mathrm{NO}_{2}{ }^{-}$. Eyers et al. (2008) proposed that an insoluble Fe(III) coating can be formed on the surface of $P$. aeruginos a cells in the presence of ferrihydrite under oxygen-depleted conditions. This process might have led to the inhibition of nitrite utilization released during TNT denitration by $P$. aeruginosa ESA-5. Under our experimental conditions no statistically reliable $\mathrm{N}_{2} \mathrm{O}$ production was detected (by GC analysis) and Fe-enriched layers on 
the yeast cells could not be observed using scanning electron microscopy (data not shown).

This research demonstrates that the presence of ferrihydrite has the potential to slightly decrease the rates of TNT transformation by $Y$. lipolytica AN-L15. However, against expectations, aromatic ring reduction associated with TNT-hydride complex formation still proceeds at rates very similar to systems without iron minerals. The hydride complex formation allows for the cleavage of the TNT "backbone" with nitrogen release and subsequent mineralization of TNT. In contrast to many studies in which nitro group reduction was promoted in the presence of iron, an increase in potentially toxic nitro group reduction products does not occur. Hence, the results of this study indicate that TNT transformation via hydride-Meisenheimer complexes by the yeast cells continues to be an important pathway for TNT transformation even in the presence of iron minerals. Thus, TNT transformation by yeasts potentially provides a pathway for complete TNT transformation even in iron-rich waters and soils. Therefore, the results of this study are of significance for the prospective bioremediation of sites contaminated with polynitroaromatics that contain significant amounts of Fe-minerals.

Acknowledgments This work was supported by a grant from the Ministry of Education and Science of the Russian Federation (2010-2011) and partially supported by a grant "Alğarıs" from the Republic of Tatarstan (Russia). Partial financial support was provided by the US Department of Defense, Army Research Office, Grant No. DAAD19-03-C-0103 and the Office of Science (BER), U.S. Department of Energy, Grant No. DE-FG02-03ER63582. The authors acknowledge funding for the establishment of the Environmental and Biofilm Mass Spectrometry Facility through the Defense University Research Instrumentation Program (DURIP) Contract No. W911NF0510255. We gratefully acknowledge Alexander Rodionov (Institute of Physics, Kazan Federal University) for ESR spectroscopy assistance.

\section{References}

Adamia G, Ghoghoberidze M, Graves D, Khatisashvili G, Kvesitadze G, Lomidze E, Ugrekhelidze D, Zaalishvili G (2006) Absorption, distribution, and transformation of TNT in higher plants. Ecotoxicol Environ Saf 64:136-145

Agrawal A, Tratnyek PG (1996) Reduction of nitro aromatic compounds by zero-valent iron metal. Environ Sci Technol 30:153-160

Aguiar A, de Souza-Cruz PB, Ferraz A (2006) Oxalic acid, $\mathrm{Fe}^{3+}$-reduction activity and oxidative enzymes detected in culture extracts recovered from Pinus taeda wood chips biotreated by Ceriporiopsis subvermispora. Enzym Microb Technol 38:873-878

Boparai HK, Comfort SD, Shea PJ, Szecsody JE (2008) Remediating explosive-contaminated groundwater by in situ redox manipulation (ISRM) of aquifer sediments. Chemosphere 71:933-941

Boparai HK, Comfort SD, Satapanajaru T, Szecsody JE, Grossl PR, Shea PJ (2010) Abiotic transformation of high explosives by freshly precipitated iron minerals in aqueous $\mathrm{Fe}^{\mathrm{II}}$ solutions. Chemosphere 79:865-872

Borch T, Gerlach R (2004) Use of reversed-phase high-performance liquid chromatography-diode array detection for complete separation of 2,4,6-trinitrotoluene metabolites and EPA Method 8330 explosives: influence of temperature and an ion-pair reagent. J Chromatogr A 1022:83-94

Borch T, Inskeep WP, Harwood JA, Gerlach R (2005) Impact of ferrihydrite and anthraquinone-2,6-disulfonate on the reductive transformation of 2,4,6-trinitrotoluene by a gram-positive fermenting bacterium. Environ Sci Technol 39:7126-7133

Cai Q, Zhang W, Yang Z (2001) Stability of nitrite in wastewater and its determination by ion chromatography. Anal Sci 17:917-920

Coby AJ, Picardal FW (2005) Inhibition of $\mathrm{NO}_{3}{ }^{-}$and $\mathrm{NO}_{2}{ }^{-}$ reduction by microbial $\mathrm{Fe}(\mathrm{III})$ reduction: evidence of a reaction between $\mathrm{NO}_{2}{ }^{-}$and cell surface bound $\mathrm{Fe}^{2+}$. Appl Environ Microbiol 71:5267-5274

Cudennec Y, Lecerf A (2006) The transformation of ferrihydrite into goethite or hematite, revisited. J Solid State Chem 179: 716-722

Eilers A, Rüngeling E, Stündl UM, Gottschalk G (1999) Metabolism of 2,4,6-trinitrotoluene by the white-rot fungus Bjerkandera adusta DSM 3375 depends on cytochrome $P$ 450. Appl Microbiol Biotechnol 53:75-80

Esteve-Núñez A, Caballero A, Ramos JL (2001) Biological degradation of 2,4,6-trinitrotoluene. Microbiol Mol Biol Rev 65:335-352

Eyers L, Stenuit B, Agathos SN (2008) Denitration of 2,4,6trinitrotoluene by Pseudomonas aeruginosa ESA-5 in the presence of ferrihydrite. Appl Microbiol Biotechnol 79: 489-497

Fiorella PD, Spain JC (1997) Transformation of 2,4,6-trinitrotoluene by Pseudomonas pseudoalcaligenes JS52. App1 Environ Microbiol 63:2007-2015

French CE, Nicklin S, Bruce NC (1998) Aerobic degradation of 2,4,6-trinitrotoluene by Enterobacter cloacae PB2 and by pentaerythritol tetranitrate reductase. Appl Environ Microbiol 64:2864-2868

Fujii H, Berliner LJ (1999) Ex vivo EPR detection of nitric oxide in brain tissue. Magn Reson Med 42:599-602

Hannink NK, Rosser SJ, French CE, Bruce NC (2003) Uptake and metabolism of TNT and GTN by plants expressing bacterial pentaerythritol tetranitrate reductase. Water Air Soil Pollut 3:251-258

Harter DR (1985) The use and importance of nitroaromatic chemicals in the chemical industry. In: Rickert DE (ed) Toxicity of nitroaromatic compounds. Hemisphere Publishing Corporation, Washington, pp 1-14

Hawari J, Halasz A, Beaudet S, Paquet L, Ampleman G, Thiboutot S (1999) Biotransformation of 2,4,6-trinitrotoluene with Phanerochaete chrysosporium in agitated cultures at pH 4.5. Appl Environ Microbiol 65:2977-2986 
Heiss G, Knackmuss HJ (2002) Bioelimination of trinitroaromatic compounds: immobilization versus mineralization. Curr Opin Microbiol 5:282-287

Hofstetter TB, Heijman CG, Haderlein SB, Holliger C, Schwarzenbach RP (1999) Complete reduction of TNT and other (poly)nitroaromatic compounds under iron-reducing subsurface conditions. Environ Sci Technol 33:1479-1487

Hofstetter TB, Neumann A, Schwarzenbac RP (2006) Reduction of nitroaromatic compounds by $\mathrm{Fe}$ (II) species associated with iron-rich smectites. Environ Sci Technol 40:235-242

Huang S, Lindahl PA, Wang C, Bennett GN, Rudolph FB, Hughes JB (2000) 2,4,6-Trinitrotoluene reduction by carbon monoxide dehydrogenase from Clostridium thermoaceticum. Appl Environ Microbiol 66:1474-1478

Hundal LS, Singh J, Bier EL, Shea PJ, Comfort SD, Powers WL (1997) Removal of TNT and RDX from water and soil using iron metal. Environ Pollut 97:55-64

Leung KH, Yao M, Stearns R, Chiu S-HL (1995) Mechanism of bioactivation and covalent binding of 2,4,6-trinitrotoluene. Chem Biol Interact 97:37-51

Lovley DR, Phillips EJP (1987) Rapid assay for microbially reducible ferric iron in aquatic sediments. Appl Environ Microbiol 53:1536-1540

Michels J, Gottschalk G (1994) Inhibition of lignin peroxidase of Phanerochaete chrysosporium by hydroxylamino-dinitrotoluene, an early intermediate in the degradation of 2,4,6-trinitrotoluene. Appl Environ Microbiol 60:187-194

Morgan B, Lahav O (2007) The effect of pH on the kinetics of spontaneous $\mathrm{Fe}(\mathrm{II})$ oxidation by $\mathrm{O}_{2}$ in aqueous solutionbasic principles and a simple heuristic description. Chemosphere 68:2080-2084

Nefso EK, Burns SE, McGrath CJ (2005) Degradation kinetics of TNT in the presence of six mineral surfaces and ferrous iron. J Hazard Mater 123:79-88

Nepovim A, Hebner A, Soudek P, Gerth A, Thomas H, Smrcek S, Vanek T (2005) Degradation of 2,4,6-trinitrotoluene by selected helophytes. Chemosphere 60:1454-1461

Oh SY, Cha DK, Kim BJ, Chiu PC (2002) Effect of adsorption to elemental iron on the transformation of 2,4,6-trinitrotoluene and hexahydro-1,3,5-trinitro-1,3,5-triazine in solution. Environ Toxicol Chem 21:1384-1389

Pak JW, Knoke KL, Noguera DR, Fox BG, Chambliss GH (2000) Transformation of 2,4,6-trinitrotoluene by purified xenobiotic reductase B from Pseudomonas fluorescens I-C. Appl Environ Microbiol 66:4742-4750

Rieger PG, Knackmuss HJ (1995) Basic knowledge and perspectives on biodegradation of 2,4,6-TNT and related nitroaromatic compounds in contaminated soil. In: Spain JC (ed) Biodegradation of nitroaromatic compounds. Plenum, New York, pp 1-18

Rylott EL, Lorenz A, Bruce NC (2011) Biodegradation and biotransformation of explosives. Curr Opin Biotechnol 22: 434-440

Scheibner K, Hofrichter M, Herre A, Michels J, Fritsche W (1997) Screening for fungi intensively mineralizing 2,4,6trinitrotoluene. Appl Microbiol Biotechnol 47:452-457
Singh B, Kaur J, Singh K (2012) Microbial remediation of explosive waste. Crit Rev Microbiol 38:152-167

Spain JC (1995) Biodegradation of nitroaromatic compounds. Annu Rev Microbiol 49:523-555

Stenuit BA, Agathos SN (2010) Microbial 2,4,6-trinitrotoluene degradation: could we learn from (bio)chemistry for bioremediation and vice versa? Appl Microbiol Biotechnol 88:1043-1064

Stenuit BA, Eyers L, Fantroussi SE, Agathos SN (2005) Promising strategies for the mineralization of 2,4,6-trinitrotoluene. Rev Environ Sci Bio/Technol 4:39-60

Ueno T, Suzuki Y, Fujii S, Vanin AF, Yoshimura T (2002) In vivo nitric oxide transfer of a physiological NO carrier, dinitrosyl dithiolato iron complexes, to target complexes. Biochem Pharmacol 63:485-493

van Aken B, Hofrichter M, Scheibner K, Hatakka AI, Naveau H, Agathos SN (1999) Transformation and mineralization of 2,4,6-trinitrotoluene (TNT) by manganese peroxidase from the white-rot basidiomycete Phlebia radiate. Biodegradation 10:83-91

van Dillewijn P, Couselo JL, Corredoira E, Delgado A, Wittich RM, Ballester A, Ramos JL (2008a) Bioremediation of 2,4,6-trinitrotoluene by bacterial nitroreductase expressing transgenic aspen. Environ Sci Technol 42:7405-7410

van Dillewijn P, Wittich RM, Caballero A, Ramos JL (2008b) Type II hydride transferases from different microorganisms yield nitrite and diarylamines from polynitroaromatic compounds. Appl Environ Microbiol 74:6820-6823

Vanin AF, Liu X, Samouilov A, Stukan RA, Zweier JL (2000) Redox properties of iron-dithiocarbamates and their nitrosyl derivatives: implications for their use as traps of nitric oxide in biological systems. Biochim Biophys Acta 1474:365-377

Vorbeck C, Lenke H, Fischer P, Spain JC, Knackmuss HJ (1998) Initial reductive reactions in aerobic microbial metabolism of 2,4,6-trinitrotoluene. Appl Environ Microbiol 64:246-252

Wittich RM, Ramos JL, van Dillewijn P (2009) Microorganisms and explosives: mechanisms of nitrogen release from TNT for use as an $\mathrm{N}$-source for growth. Environ Sci Technol 43:2773-2776

Ye J, Singh A, Ward OP (2004) Biodegradation of nitroaromatics and other nitrogen-containing xenobiotics. World $\mathrm{J}$ Microbiol Biotechnol 20:117-135

Yinon J (1990) Toxicity and metabolism of explosives. CRC Press, Boca Raton

Ziganshin AM, Gerlach R, Borch T, Naumov AV, Naumova RP (2007) Production of eight different hydride complexes and nitrite release from 2,4,6-trinitrotoluene by Yarrowia lipolytica. Appl Environ Microbiol 73:7898-7905

Ziganshin AM, Naumova RP, Pannier AJ, Gerlach R (2010a) Influence of $\mathrm{pH}$ on 2,4,6-trinitrotoluene degradation by Yarrowia lipolytica. Chemosphere 79:426-433

Ziganshin AM, Gerlach R, Naumenko EA, Naumova RP (2010b) Aerobic degradation of 2,4,6-trinitrotoluene by the yeast strain Geotrichum candidum AN-Z4. Microbiology 79:199-205 